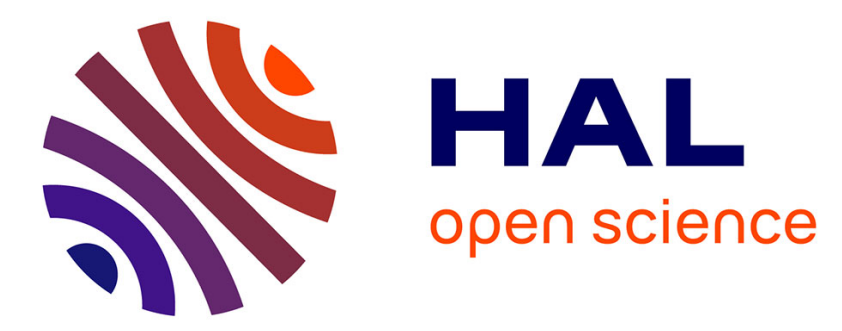

\title{
Real-time quantitative analysis of volatile products generated during solid-state polypropylene thermal oxidation
}

\author{
Alexandre Francois-Heude, Emmanuel Richaud, Julien Leprovost, Michel \\ Heninger, Helene Mestdagh, Eric Desnoux, Xavier Colin
}

\section{To cite this version:}

Alexandre Francois-Heude, Emmanuel Richaud, Julien Leprovost, Michel Heninger, Helene Mestdagh, et al.. Real-time quantitative analysis of volatile products generated during solid-state polypropylene thermal oxidation. Polymer Testing, 2013, 32, pp.907-917. 10.1016/j.polymertesting.2013.04.008 . hal-00987223

\section{HAL Id: hal-00987223 \\ https://hal.science/hal-00987223}

Submitted on 6 May 2014

HAL is a multi-disciplinary open access archive for the deposit and dissemination of scientific research documents, whether they are published or not. The documents may come from teaching and research institutions in France or abroad, or from public or private research centers.
L'archive ouverte pluridisciplinaire HAL, est destinée au dépôt et à la diffusion de documents scientifiques de niveau recherche, publiés ou non, émanant des établissements d'enseignement et de recherche français ou étrangers, des laboratoires publics ou privés. 


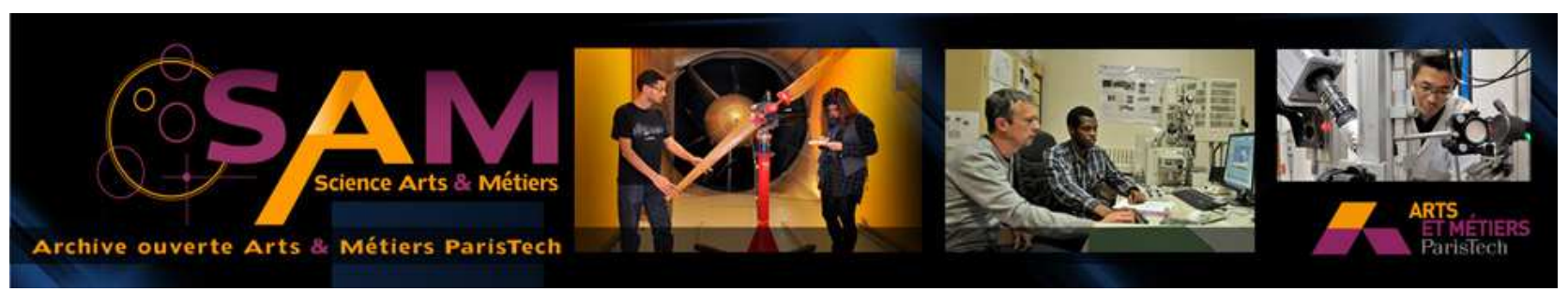

\section{Science Arts \& Métiers (SAM)}

is an open access repository that collects the work of Arts et Métiers ParisTech researchers and makes it freely available over the web where possible.

This is an author-deposited version published in: http://sam.ensam.eu

Handle ID: .http://hdl.handle.net/10985/8098

\section{To cite this version :}

Alexandre FRANCOIS-HEUDE, Emmanuel RICHAUD, Julien LEPROVOST, Michel HENINGER, Helene MESTDAGH, Eric DESNOUX, Xavier COLIN - Real-time quantitative analysis of volatile products generated during solid-state polypropylene thermal oxidation - Polymer Testing - Vol. 32, p.907-917. - 2013 
Material behaviour

\title{
Real-time quantitative analysis of volatile products generated during solid-state polypropylene thermal oxidation
}

\author{
Alexandre François-Heude ${ }^{\mathrm{a}, \mathrm{c}, *}$, Emmanuel Richaud ${ }^{\mathrm{a}}$, Julien Leprovost ${ }^{\mathrm{b}}$, \\ Michel Heninger ${ }^{b, d}$, Helene Mestdagh ${ }^{d}$, Eric Desnoux ${ }^{c}$, Xavier Colin $^{a}$ \\ a PIMM, UMR CNRS 8006, ARTS ET METIERS ParisTech, Paris, France \\ ${ }^{\mathrm{b}}$ ALYXAN, Orsay, France \\ ${ }^{\mathrm{c}}$ DREAM-DIMAT Department, RENAULT, Guyancourt, France \\ ${ }^{\mathrm{d}}$ LCP, UMR8000, Bât 350, Université Paris-Sud, 91405 Orsay Cedex, France
}

Keywords:

Polypropylene oxidation

Volatile organic compounds

Mass spectrometry

Chain scission mechanisms

\section{A B S T R A C T}

Analysis of volatile organic compounds (VOCs) during PP thermal oxidation under three oxygen partial pressures $\left(0 \%, 21 \%\right.$ and $100 \%$ of atmospheric pressure) at $140{ }^{\circ} \mathrm{C}$ was performed by proton transfer reaction coupled with Fourier transform ion cyclotron resonance mass spectrometry. Six main VOCs were identified: acetone, acetic acid, 2,4pentanedione, acetaldehyde, formaldehyde and methyl acrolein. Their formation was shown to obey two main reaction pathways, both involving methyne units as driving oxidation sites: (i) the widely accepted chain scission mechanism of tertiary alkoxy radicals, which generates primary radicals undergoing secondary reactions leading to the oxidation of methylene units; (ii) the chain scission mechanism occurring on tertiary alkyl radical, which is proposed here as a realistic path leading to methyl acrolein. The relative proportions of the six main VOCs depend on the oxygen partial pressure, which mostly impacts the oxidation of methylene units rather than the competition between the two previous paths.

\section{Introduction}

Analysis of Volatile Organic Compounds (VOCs) emitted during degradation of polypropylene (PP) has been widely studied during the last three decades under various exposure conditions such as photo-oxidation [1-3], radiooxidation [4-6] and thermal oxidation in both solid and molten states [7-14]. Many VOCs were identified, particularly in thermal oxidation by Hoff et al. [15] or more recently by Bernstein et al. [8]. Moreover, except for a recurrent group of VOCs, multiple products were identified

\footnotetext{
* Corresponding author. PIMM, UMR CNRS 8006, ARTS ET METIERS ParisTech, 151, Boulevard de l'Hôpital, Paris 75013, France. Tel.: +33 144 2464 13; fax: +33144246382. Heude).
}

by the different authors even for similar ageing conditions, possibly due to:

(i) The existence of a potential degradation of primary VOCs occurring between the sample and the detector,

(ii) The presence of residues or degradation products from "contaminants" such as additives,

(iii) The use of different ageing conditions generating a large range of minor products.

Most of the previous authors tried to quantify VOCs by trapping them and subsequently performing titration by gas chromatography, often coupled with mass spectrometry (GC-MS).

Identification and quantification of VOCs brought valuable information about the prevailing mechanisms of polypropylene oxidation, consistent with their precursory 
macromolecular oxidation products $[1,3-5,7,16,17]$. VOCs analysis was particularly applied to the determination of the relative sensitivities to oxidation of methyne and methylene -besides methyl- units to oxidation [8]. It was confirmed that methyne units are about 10 times more reactive than the methylene ones, as in previous results obtained on macromolecular oxidation products by derivatization methods [18] or isotope labeling [17]. Basing on such mechanistic considerations, i.e. only considering the oxidation of methyne units in a first approach, a "closed loop" mechanistic scheme was proposed to describe the general oxidation path [19]. Using kinetic modeling, such an approach enables determination of the amount of chain scission generated and its impact on the polypropylene mechanical properties [20] or mass loss [21]. In the case of kinetic modeling of ethylene-propylene copolymers, the reactivities of both methyne and methylene sites were considered as mainly due to the higher content of methylene units [22]. However, these results are not transposable to the case of isotactic polypropylene where the tacticity -and the subsequent conformational effect- would change the relative reactivities of both sites [23]. The impact of methylene units on the oxidation in polypropylene, although considered as minority in a first approach, is thus questionable.

A reliable quantitative analysis of volatiles is expected to give additional information about the prevalence of the PP oxidation mechanisms, among them the minority impact of methylene oxidation, but also about their impact on the subsequent property changes. Recently, Chemical Ionization (analyte ionization through chemical reaction with a specific ionic precursor) associated with Fourier Transform Ion Cyclotron Resonance Mass Spectrometry (CI-FTICR) was shown to be a powerful technique to perform quantitative and real-time analysis of VOCs emission during the thermal oxidation of PP in the molten state $\left(256{ }^{\circ} \mathrm{C}\right)$ [24].

The aim of this study was to apply VOCs real-time analysis to the study of PP thermal oxidation in the solid state $\left(140{ }^{\circ} \mathrm{C}\right)$ under different oxygen partial pressures $(0 \%$, $21 \%$ or $100 \%$ of atmospheric pressure), since it was shown that this last factor can significantly influence the overall oxidation kinetics of PP [25]. More precisely, the issue here is the impact of oxygen pressure on both methylene and methyne site reactivities, polyethylene and polypropylene having been shown to have very different critical oxygen pressures, and hence, different oxygen pressure dependencies [26]. The consequences of oxygen pressure on the released VOC will be interpreted in terms of competitive pathways, established from a comprehensive review of mechanistic schemes proposed for prevailing VOCs.

\section{Experimental section}

\subsection{Materials}

Isotactic polypropylene $\left(M_{W}=250,000 \mathrm{~g} / \mathrm{mol}\right.$ and $M_{n}=67,000 \mathrm{~g} / \mathrm{mol}$ ) was supplied by Aldrich and processed to produce $80-150 \mu \mathrm{m}$ films by compression molding. All films were purified from antioxidants by Soxhlet extraction with dichloromethane for $48 \mathrm{~h}$ prior to thermal ageing experiments.

\subsection{Analysis}

The thermal oxidation kinetics of PP was followed at $140{ }^{\circ} \mathrm{C}$ under air and pure oxygen by three analytical techniques: (i) CI-FTICR as described below, using proton transfer reaction (PTR) as specific CI reaction; (ii) Fourier transformed infrared spectroscopy (FTIR), performed with a Perkin-Elmer device (16 scans, minimal resolution of $4 \mathrm{~cm}^{-1}$ ); (iii) thermogravimetric analyses (TGA) performed on samples of about 14-16 mg with a TA Instruments TGA Q50 apparatus equipped with an Alytech GasMix unit.

\subsection{PTR-FTICR: apparatus \& methods}

Under air and pure oxygen, samples of $158.7 \mathrm{mg}$ and $30.2 \mathrm{mg}$ (i.e. slices of 80 to $150 \mu \mathrm{m}$ thickness) were put into a small quartz vessel and introduced into the preheated oven at zero time. The temperature was stabilized at $140^{\circ} \mathrm{C}$. The sample was swept by a controlled gas mixture flow generated by the AlyTech GasMix device. The gas flow was continuously sampled by the mass spectrometer, providing real time analysis of VOCs emission. VOCs analysis were performed with a BTrap mass spectrometer device, the specifications and analysis procedure of which were described in detail in a previous publication [24]. The experimental setup is schematized in Fig. 1.

Briefly, BTrap instruments are compact and transportable mass spectrometers based on the FTICR technique, allowing trapping of ions and detecting them by their mass-to-charge $(\mathrm{m} / \mathrm{z})$ ratio. The strong and homogeneous magnetic field required by this technique is generated by a structured permanent magnet [27], providing a $1 \mathrm{~T}$ magnetic field for the instrument used in the present work.

Each recorded mass spectrum results from a programmed sequence including successive precursor ion generation, sample introduction, ion-molecule reaction during a controlled time, and ion detection. The whole sequence is performed in the FTICR cell with a total duration that does not exceed $1 \mathrm{~s}$. The cell is maintained at a pressure in the range from $\leq 10^{-8}$ mbar during ion detection to $10^{-6}$ mbar during sample introduction.

In the present study, the $\mathrm{CI}$ precursor consists of $\mathrm{H}_{3} \mathrm{O}^{+}$ ions. These ions are generated by electron ionization of

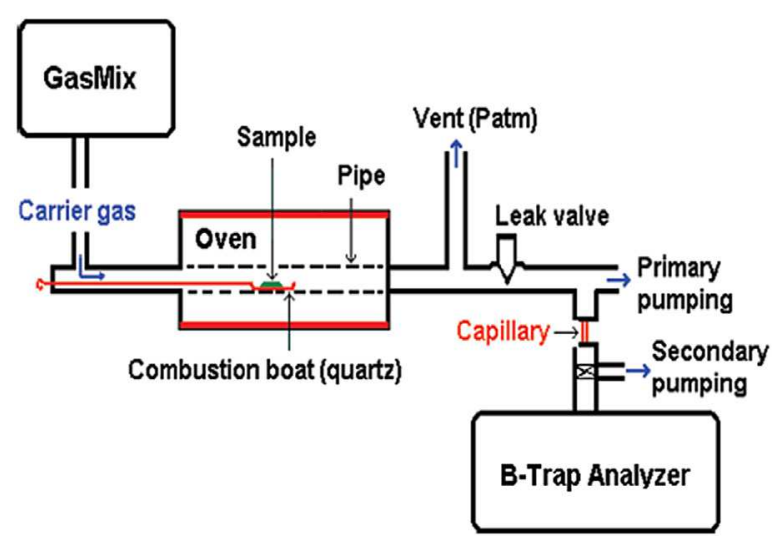

Fig. 1. PTR-FTICR experimental setup. 
$\mathrm{H}_{2} \mathrm{O}$, followed by ion-molecule reaction leading to $\mathrm{H}_{3} \mathrm{O}^{+}$ terminal ions. On sample introduction, these ions react with each VOC denoted $\mathrm{M}_{\mathrm{i}}$ by proton transfer, leading to the protonated ion $\mathrm{M}_{\mathrm{i}} \mathrm{H}^{+}$:

$$
\mathrm{H}_{3} \mathrm{O}^{+}+\mathrm{M}_{i} \rightarrow \mathrm{H}_{2} \mathrm{O}+\mathrm{M}_{i} \mathrm{H}^{+}
$$

This reaction occurs rapidly for any VOC bearing unsaturation and/or a $\mathrm{N}$ or $\mathrm{O}$ atom. Therefore, the resulting mass spectrum contains a peak corresponding to unreacted $\mathrm{H}_{3} \mathrm{O}^{+}$, and a variable number of peaks corresponding to $\mathrm{M}_{\mathrm{i}} \mathrm{H}^{+}$ions arising from protonation of $\mathrm{M}_{\mathrm{i}}$ molecules. Recorded intensities of the ions, along with knowledge of the operating parameters and the rate constant of the PTR reaction, allow VOC quantification as explained in the following:

According to the classical theory of chemical kinetics:

$\frac{d\left[\mathrm{H}_{3} \mathrm{O}^{+}\right]}{d t}=-\left[\mathrm{H}_{3} \mathrm{O}^{+}\right] \mathrm{S}$

where $S=\sum\left[k_{i}\left[M_{i}\right]\right]$ is the sum of all $k_{i}\left[M_{i}\right]$ terms corresponding to the molecules $\mathrm{M}_{i}$ undergoing protonation by $\mathrm{H}_{3} \mathrm{O}^{+}$and:

$\frac{d\left[M_{i} H^{+}\right]}{d t}=k\left[M_{i}\right]\left[H_{3} O^{+}\right]$

The resolution of the system of differential equations leads to the expression:

$\left[M_{i}\right]=\frac{\ln \left(H_{3} O^{+}\right) \times\left(M_{i} H^{+}\right)}{k_{i} \tau\left(1-\left(H_{3} O^{+}\right)\right)}$

where $\tau$ is the reaction time, $\left(\mathrm{H}_{3} \mathrm{O}^{+}\right)$and $\left(\mathrm{M}_{i} \mathrm{H}^{+}\right)$the relative intensities of the corresponding ions, normalized to the sum of all ion intensities.
The gas pulse of analytes was adjusted to $250 \mathrm{~ms}$ to increase the sensitivity. Under these conditions, the conversion rate of the reaction is kept under $30 \%$ to avoid secondary reactions.

The concentration $C_{i}$ in the gas flow for the component $\mathrm{M}_{i}$ is derived from its concentration $\left[M_{i}\right]$ in the ICR cell according to:

$C_{i}=\left[M_{i}\right] \frac{P_{\text {flow }}}{P_{\text {cell }}}$

In the present work, the corrected cell pressure was $1.99 \times 10^{-5}$ and $2.13 \times 10^{-5}$ Torr under air and pure oxygen respectively.

With $P_{\text {flow }}=1$ bar, the following relationship is obtained:

$C_{i}\left(\frac{m o l}{L}\right)=1.26 \cdot 10^{-18} \frac{\left[M_{i}\right]\left(\mathrm{cm}^{-3}\right)}{P_{\text {cell }}(\text { torr })}$

The total amount $N_{i}$ of a compound $M_{i}$ emitted by pyrolysis of a sample at a given time $t$ is expressed as:

$N_{i}(t)=\int d n_{i}=\int_{0}^{t} C_{i}(t) d t$

where $C_{i}(t)$ (in $\mathrm{mol} / \mathrm{L}$ ) is the instantaneous concentration of $M_{i}$ in the gas flow and $F(\mathrm{~L} / \mathrm{min})$ is the volume flow rate of the carrier gas.

Adjusting the carrier gas flow $F$ to $50 \mathrm{~mL} / \mathrm{min}$, the resulting transport time is $1.50 \mathrm{~min}$. This time was systematically subtracted from the time measured from sample introduction.

An example of real-time data acquisition is depicted in Fig. 2.

Since the previous work, several technical improvements have been brought to the instrument, resulting in

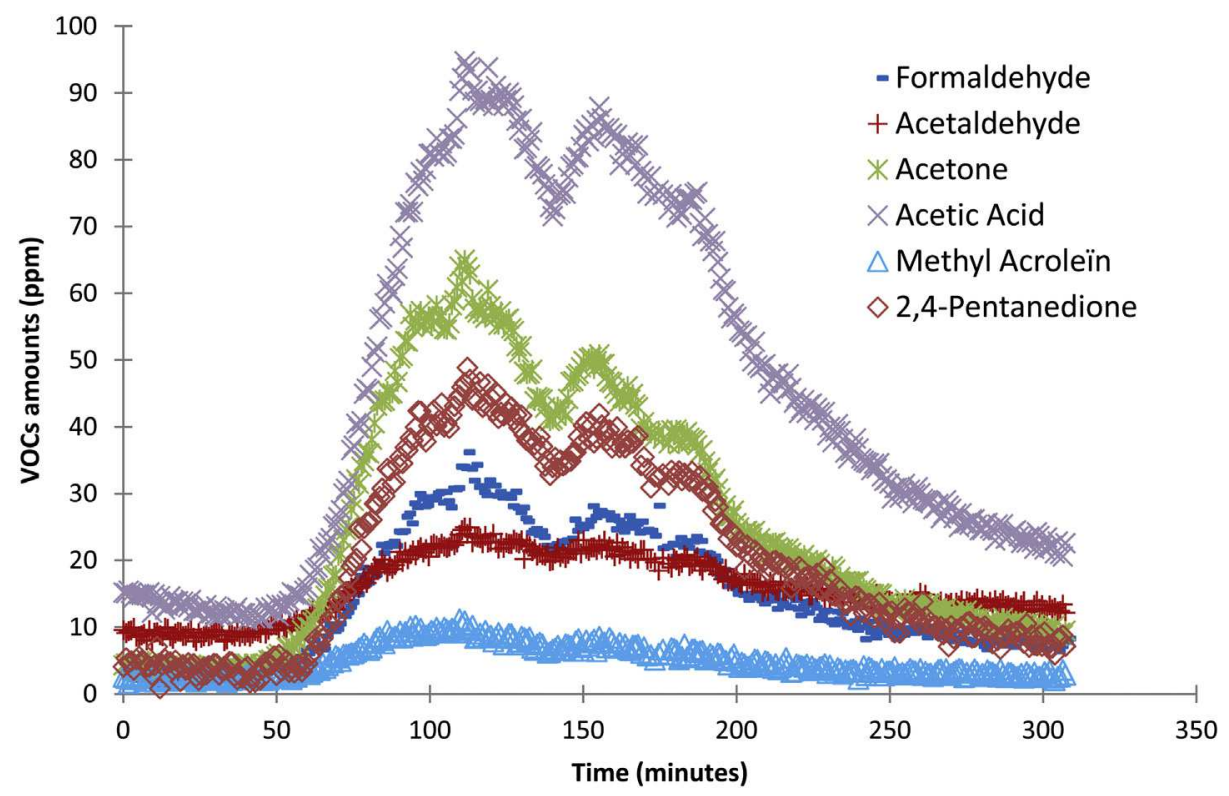

Fig. 2. Real-time monitoring of VOCs generation in pure oxygen at $140{ }^{\circ} \mathrm{C}$. 
increased sensitivity, easier software and real-time pressure measurement in the FTICR cell. This direct pressure monitoring provides reliable control of the sample amount introduced into the mass spectrometer during each gas pulse. The uncertainty of this absolute quantification method is $25 \%$, mainly due to the uncertainty on the rate constant, ranging between 15\% (for acetone) and 30\% for the quantitative mode, whereas the semi-quantitative mode gives the right order of magnitude. It was shown that the amount of VOCs is a linear function of the initial sample mass.

\section{Results and discussion}

\subsection{Real-time analysis: identification and quantification of VOCS}

PTR-FTICR analysis evidences numerous VOCs during PP thermal oxidation in air and pure oxygen. They only differ by their relative proportions. No trace of VOCs is found in nitrogen atmosphere at the same temperature, even for extended duration (up to $1000 \mathrm{~min}$ ) and high initial sample mass. This confirms that thermolysis reactions alone do not initiate the degradation of polypropylene at the working temperature. The use of high resolution mass spectrometry enables determination of the precise molecular formula besides the mass spectra themselves. When several attributions are possible, results are systematically compared to an extensive literature review. It is thus possible to differentiate two compounds of the same nominal molecular mass, but with different exact masses (Table 1). For instance, the peak here observed at $72 \mathrm{~g} / \mathrm{mol}$ must be assigned to acrylic acid instead of butanone [4,7] or 2methyl-2-propen-1-ol $[6,8]$ as previously reported in the literature. For sake of simplicity, six main VOCs, each representing more than $5 \mathrm{~mol} \%$ of the total amount of VOCs, are considered in this study (Table 1). Among the minor products, acrylic acid, 1-hydroxy-2-propanone, crotonic acid, 2,4-dimethylfurane and 4-methyl-3-penten-2-one have been identified. Propylene and hept-3-ene have also been detected as non-oxygenated compounds.

As volatile emissions are reported to be responsible for the mass changes, VOCs releases can be advantageously compared to thermogravimetric data. The whole releases apply to the cumulated emissions along time, and are thus obtained by integration of real-time monitoring data (as depicted in Fig. 2). The curves are presented in Fig. 3.

Real time monitoring techniques allow determination of three different characteristic times:
- The onset time corresponding to the first detectable VOCs emission, mass changes and build-up of macromolecular carbonyl products.

- The induction time corresponding to the establishment of the steady-state regime in these three kinetic curves. In general, it is arbitrarily determined by intercepting the steady-state straight-line with the $\mathrm{x}$-abscissa.

- The time of maximal mass gain corresponding to the position of the maximum value in thermogravimetric curves.

Their values, determined at $140{ }^{\circ} \mathrm{C}$ under both air and pure oxygen, are summarized in Table 2.

VOCs emission clearly starts after mass increase and formation of the first macromolecular carbonyl products but, as expected, when mass loss becomes predominant over mass gain. Obviously, this is a "coarse grained tendency" since the three physico-chemical techniques under consideration have not been coupled in this study. However, given the low scattering of experimental results, no doubt it is a real characteristic of the PP thermal oxidation kinetics [21].

These results are consistent with the previous assumption on PP thermal oxidation mechanism [28]. First, the initial mass increase results from the "closed loop" character of the oxidation reaction: the initiation rate increases and the kinetic chain length decreases with time. Mass increase, due to oxygen incorporation and thus hydroperoxides accumulation, is essentially linked to propagation and predominates at the beginning of the induction period. In contrast, the build-up of macromolecular carbonyl products is due to $\beta$ scissions of alkoxy radicals induced by initiation (i.e. hydroperoxides decomposition) or non-terminating combination of (peroxy) radical pairs. Moreover, VOCs are formed when chain scissions occur at polymer chain extremities, i.e. at advanced degradation states of PP. Therefore, it is not surprising to observe the formation of macromolecular carbonyl products and the predominance of mass gain in the early period of exposure, and VOCs emissions and mass loss later (when the kinetic chain length tends towards unity).

However, the emission of VOCs begins before the end of the formation of macromolecular carbonyl products. As suggested in the literature [3], any release of carbonyl fragments (in particular pentanedione, methyl acrolein, acetic acid, acetone, acetaldehyde, formaldehyde, etc.) can affect significantly the carbonyl index measurement because VOCs are currently not measured using conventional FTIR methods following oxidation. Nonetheless, the

Table 1

Attribution of VOCs according to high-resolution mass spectrometry.

\begin{tabular}{|c|c|c|c|c|c|c|c|}
\hline $\begin{array}{l}\text { Calculated } \mathrm{M}+1 \\
\text { peak (in } \mathrm{g} / \mathrm{mol} \text { ) }\end{array}$ & $\begin{array}{l}\text { Measured } \mathrm{M}+1 \\
\text { peak (in } \mathrm{g} / \mathrm{mol} \text { ) }\end{array}$ & |Error| (\%) & $\begin{array}{l}\mathrm{M}+1 \\
\text { formula }\end{array}$ & $\begin{array}{l}\text { M } \\
\text { formula }\end{array}$ & Attribution & $\begin{array}{l}\text { Attribution according } \\
\text { to references }\end{array}$ & $\begin{array}{l}\text { Protonation kinetic } \\
\text { constant rate }\left(\text { in } \mathrm{cm}^{3} / \mathrm{s} \text { ) }\right.\end{array}$ \\
\hline 101.0535 & 101.0603 & 0.007 & $\mathrm{C}_{5} \mathrm{H}_{9} \mathrm{O}_{2}$ & $\mathrm{C}_{5} \mathrm{H}_{8} \mathrm{O}_{2}$ & 2,4-pentanedione & {$[6,8,9,14,15]$} & $1.85 \mathrm{E}-09$ \\
\hline 71.0419 & 71.0497 & 0.011 & $\mathrm{C}_{4} \mathrm{H}_{7} \mathrm{O}$ & $\mathrm{C}_{4} \mathrm{H}_{6} \mathrm{O}$ & Methyl acrolein & {$[6-8,15,24]$} & $3.80 \mathrm{E}-09$ \\
\hline 61.0211 & 61.029 & 0.013 & $\mathrm{C}_{2} \mathrm{H}_{5} \mathrm{O}_{2}$ & $\mathrm{C}_{2} \mathrm{H}_{4} \mathrm{O}_{2}$ & Acetic acid & {$[1-3,6-10,13-15]$} & 2.60E-09 \\
\hline 59.0421 & 59.0497 & 0.013 & $\mathrm{C}_{3} \mathrm{H}_{7} \mathrm{O}$ & $\mathrm{C}_{3} \mathrm{H}_{6} \mathrm{O}$ & Acetone & {$[1-4,6-15,24]$} & 3.92E-09 \\
\hline 45.027 & 45.034 & 0.016 & $\mathrm{C}_{2} \mathrm{H}_{5} \mathrm{O}$ & $\mathrm{C}_{2} \mathrm{H}_{4} \mathrm{O}$ & Acetaldehyde & {$[4,7,10,13,15,24]$} & $3.78 \mathrm{E}-09$ \\
\hline 31.0143 & 31.0184 & 0.013 & $\mathrm{CH}_{3} \mathrm{O}$ & $\mathrm{CH}_{2} \mathrm{O}$ & Formaldehyde & {$[3,11,12,15,24]$} & 3.32E-09 \\
\hline
\end{tabular}



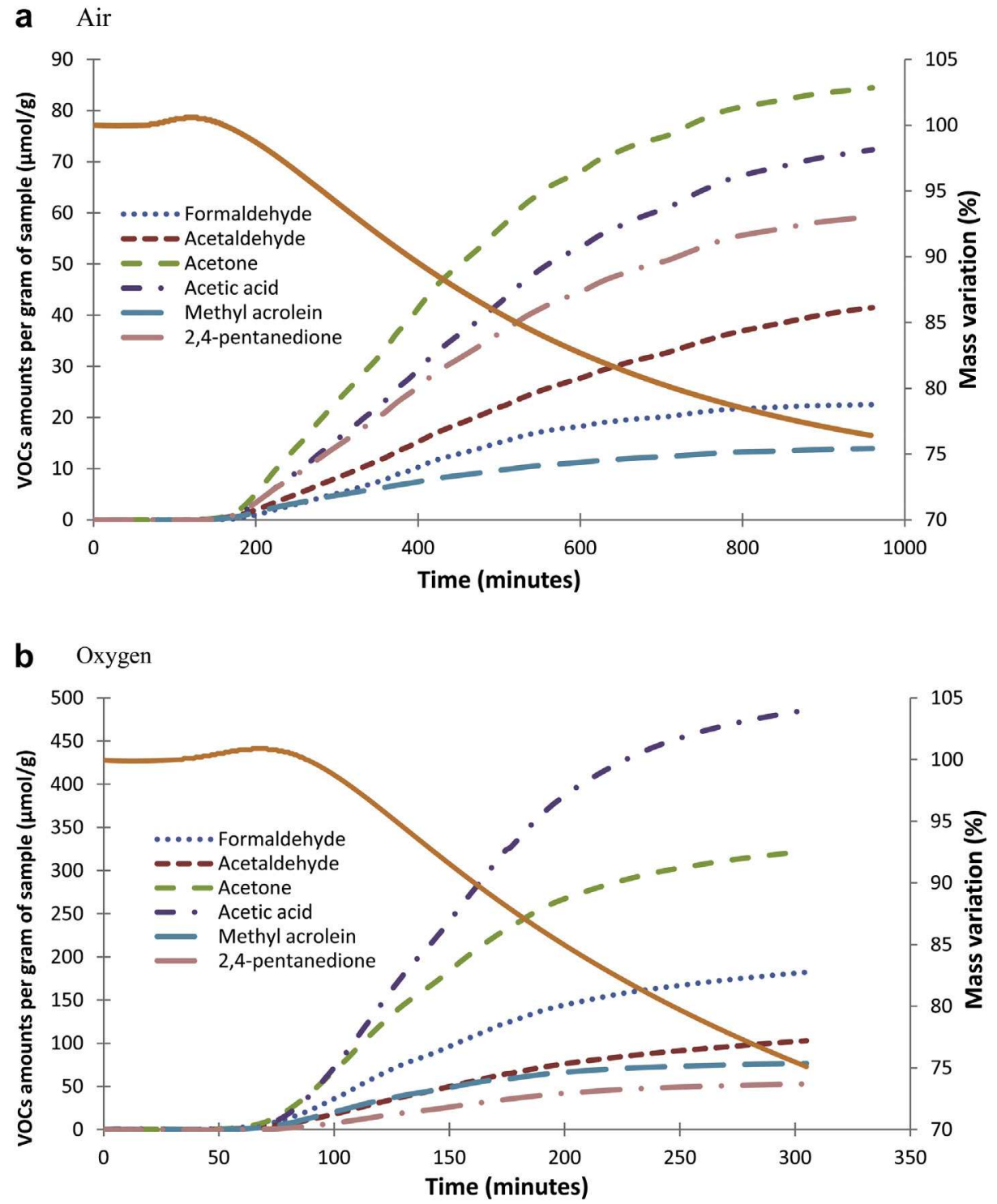

Fig. 3. Cumulated VOCs amounts normalized by the sample initial mass (left caption) and correlation with thermo-gravimetric analysis at $140{ }^{\circ} \mathrm{C}($ right caption) in air (a) and pure oxygen (b).

Table 2

Characteristic times (in minutes) for the kinetic curves of VOCs emission, mass changes and build-up of macromolecular carbonyl products (see text) at $140{ }^{\circ} \mathrm{C}$ in air and pure oxygen.

\begin{tabular}{|c|c|c|c|}
\hline In air & VOCs & Mass & $>C=O$ \\
\hline Onset time (min) & 140 & 53 & 30 \\
\hline Induction time ( $\mathrm{min}$ ) & 158 & 78 & 66 \\
\hline Time of maximal mass gain (min) & - & 129 & - \\
\hline In $\mathrm{O}_{2}$ & VOCs & Mass & $>\mathrm{C}=\mathrm{O}$ \\
\hline Onset time (min) & 60 & 31 & - \\
\hline Induction time (min) & 73 to 78 & 44 & - \\
\hline Time of maximal mass gain (min) & - & 78 & - \\
\hline
\end{tabular}

Close values of the induction time relative to VOCs release and the time of maximal mass gain are highlighted in bold. impact of this was not clearly evaluated. Thanks to realtime VOCs analysis, it is now possible to precisely quantify the impact of volatile products on the underestimation of carbonyl concentration. At $140{ }^{\circ} \mathrm{C}$ in air, for instance, the amount of released carbonyl functions -including carboxyl ones- has been obtained by cumulating VOCs, considering their functionality. It has then been added to the concentration of macromolecular carbonyl products measured at $1713 \mathrm{~cm}^{-1}$ by FTIR spectrophotometry. The theoretical concentration in carbonyl oxidation products without any VOC emission has been calculated and plotted in Fig. 4. In this case, it can be seen that VOCs emission clearly impacts the steady-state oxidation rate measured on carbonyl species, by about $70 \%$.

Moreover, carbon assessment between the mass loss and VOCs release provides evidence of some missing material: 


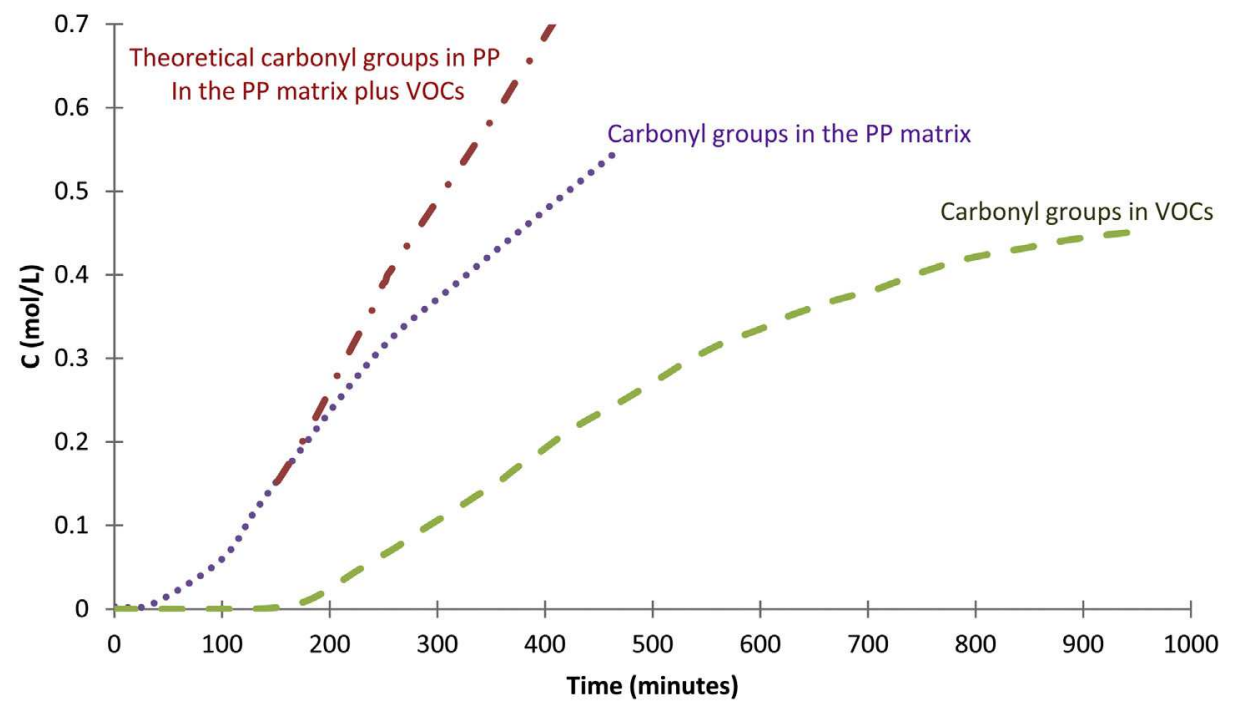

Fig. 4. Changes in the concentration of carbonyl groups in the PP matrix and VOCs at $140{ }^{\circ} \mathrm{C}$ in air. Comparison to the hypothetical concentration of carbonyl groups if no VOC was formed.

other volatile compounds would not be detected by PTRFTICR. These molecules would mainly consist of carbon monoxide, carbon dioxide, and methane in addition to water, which is a well-known by-product of initiation reactions by hydroperoxides decomposition. The contribution of each kind of volatiles to the overall weight loss, under both air (a) and oxygen exposure (b) are depicted in Fig. 5.

Under air, VOCs emission accounts for $17 \mathrm{wt} \%$ of the initial material mass, i.e. $9 \pm 2 \mathrm{~mol} \%$, whereas the small fragments account for $83 \mathrm{wt} \%$. As a consequence, the theoretical oxidation rate measured by FTIR would be still strongly underestimated. Moreover, these amounts remain almost unchanged along the entire course of PP thermal oxidation, which would suggests that mechanisms of VOCs formation do not much change even for extended state of degradation. Under pure oxygen, however, the mass loss due to VOCs emission exceeds $55 \mathrm{wt} \%$, i.e. $30 \pm 5 \mathrm{~mol} \%$. In both cases, PTR-FTICR does not detect high prevailing organic fragments of key importance for mass loss.

\subsection{Effects of oxygen pressure}

During experiments under 0.2 and 1 bar oxygen pressure, no difference in the VOCs nature is detected. In contrast, significant differences in their relative proportions of VOCs are detected (Fig. 3).

First, this phenomenon is tentatively explained by investigating the changes in reactivity of methyne and methylene units with the oxygen pressure. All VOCs, including minor ones, are classified depending on their(s) own oxidation site(s) in order to evaluate the relative proportions of reactive sites oxidized at $140{ }^{\circ} \mathrm{C}$. The oxidation site for each molecule is determined from the results in our extended review of published works. As shown in Fig. 6 , the percentages of oxidized methyne and methylene sites remain largely unchanged along the entire course of oxidation, whatever the aging atmosphere (air or pure oxygen). In air, methyne sites account for almost
$90 \mathrm{~mol} \%$ of the oxidation sites in VOCs, which is consistent with analyses performed on macromolecular oxidation products by NMR spectrometry $[5,17]$. Indeed, according to these authors, PP thermal oxidation would affect $90 \mathrm{~mol} \%$ of methyne units, $9 \mathrm{~mol} \%$ of methylene units and $1 \mathrm{~mol} \%$ of methyl units. In pure oxygen, however, methylene sites account for a higher proportion of oxidation sites: about $17 \mathrm{~mol} \%$. Thus, the reactivity of methylene sites would be also enhanced when increasing the oxygen partial pressure, which is contrary to what was expected.

To compare the impact of an increase in the oxygen partial pressure on the formation paths of volatile compounds, the ratios of their generation rates in oxygen and air have been calculated (Fig. 7). Considering a single elementary generation path for each molecular species, ratios of macroscopic rates are equal to the ratio of elementary kinetic rate constants. The macroscopic generation rates have been determined at the inflexion point on the plot of their cumulated concentrations presented in Fig. 3. The higher this ratio is for a species, the higher its sensitivity to oxygen pressure is.

As expected, for all VOCs, the ratio exceeds a value of 10 , indicating that a small increase in oxygen partial pressure (by a factor 5) induces a high increase in oxidation rate (by a factor higher than 10). This result is consistent with the previous assumption on PP thermal oxidation mechanism [28]. Indeed, it was recently shown that the critical oxygen partial pressure for oxygen excess is about $2 \mathrm{MPa}$ at $60{ }^{\circ} \mathrm{C}$ for PP and is a slow decreasing function of temperature [25]. Thus, even far below this critical pressure, PP thermal oxidation kinetics is very sensitive to oxygen partial pressure. Nonetheless, all VOCs do not undergo similar effects of oxygen partial pressure, since their respective ratios range from 10 to 26 . Only formaldehyde and acetic acid seem to be highly impacted by the change in oxygen partial pressure. It is noteworthy that these species were evidenced by Eriksson et al. to be gas-phase contributors to the spreading of oxidation in polypropylene [29]. 


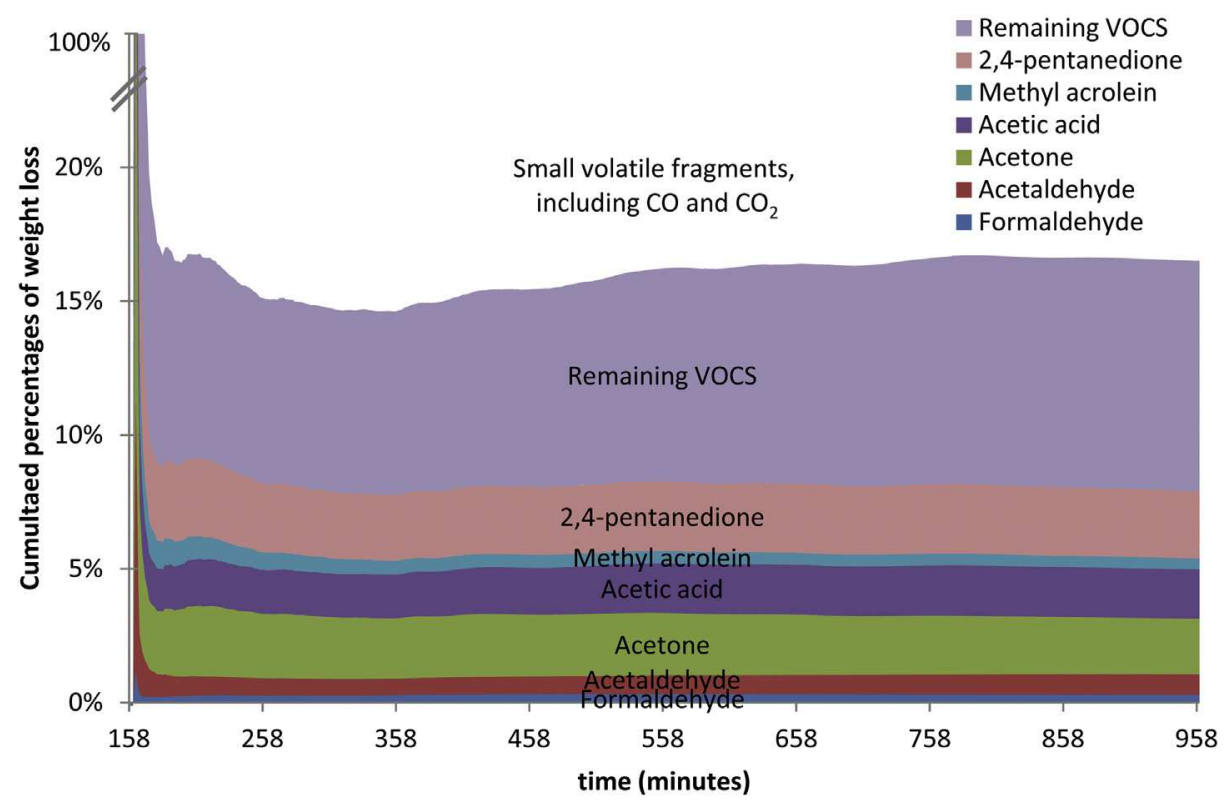

b Oxygen

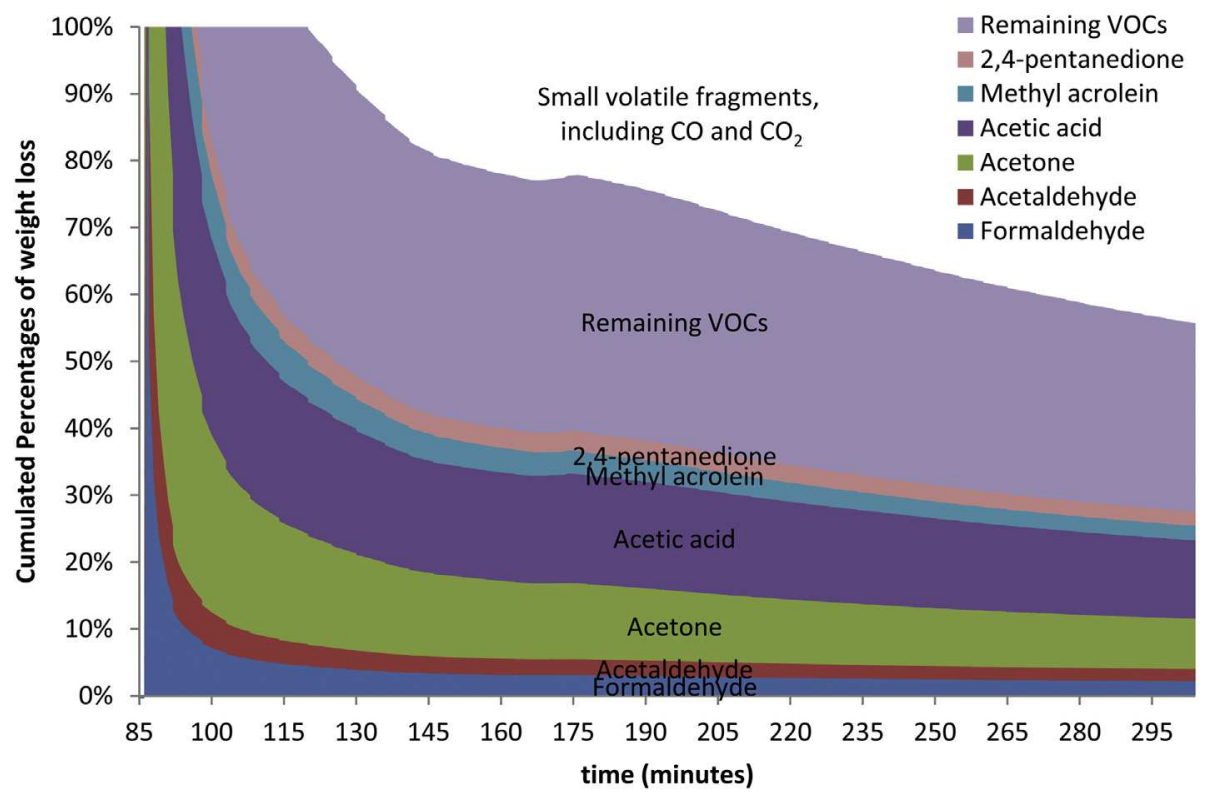

Fig. 5. Mass contribution of VOCs to PP weight loss in air (a) and pure oxygen (b); Results are only plotted after the beginning of VOCs release, as reported in Table 2.

\subsection{Mechanistic discussion}

In order to explain both the nature and the relative proportions of VOCs, an interpretation in terms of mechanisms is required. The most probable mechanisms for the six main VOCs detected by PTR-FTICR, as well as the evidenced carbon oxides, have been arbitrarily selected basing on kinetic considerations, such as probabilities of molecules collisions or lifetime of transition states, and on published experimental evidences such as isotope labeling $[5,30]$.

However, a new mechanism is proposed to explain the formation of methyl acrolein as well as carbon oxides resulting from the oxidation of tertiary carbons, whose published mechanisms are considered unrealistic. The selected mechanisms are organized in two global schemes (one dedicated to the detected VOCs and a second 


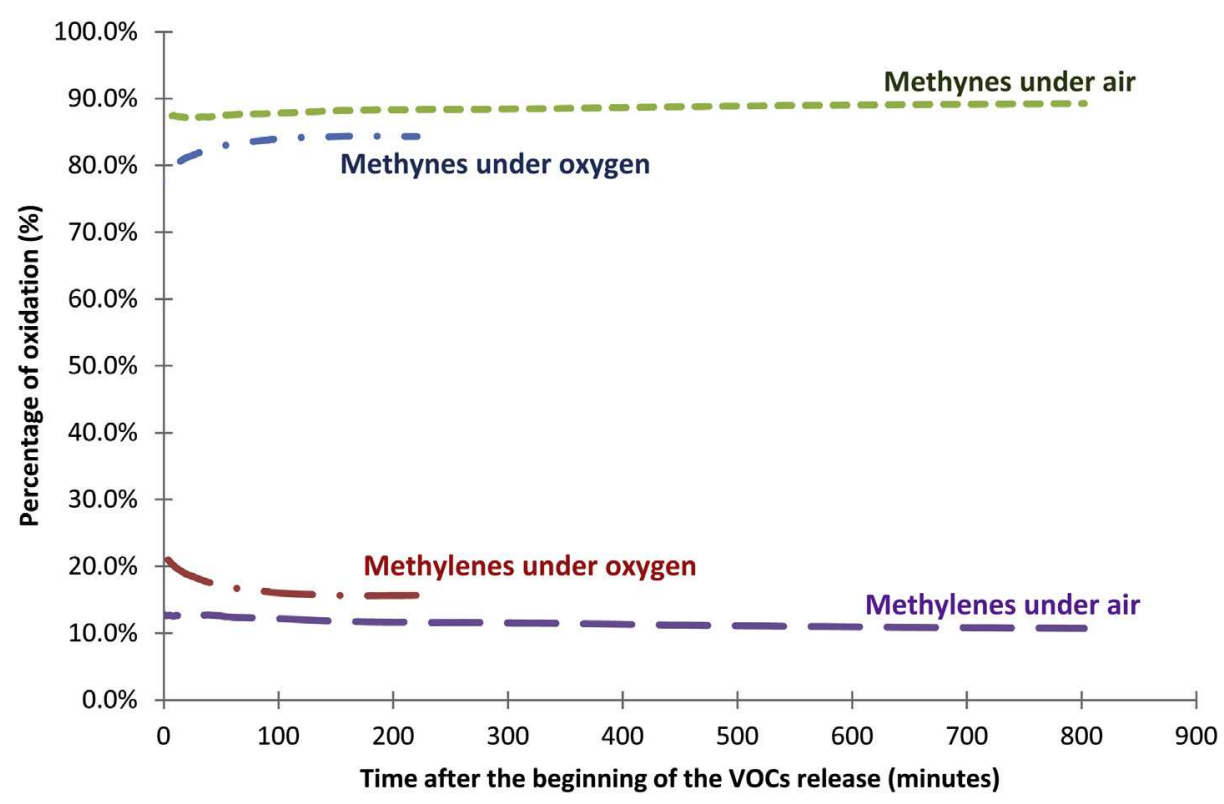

Fig. 6. Oxidation sites in volatile products in both air and pure oxygen (The initial time applies to the beginning of VOCs release for each oxygen atmosphere).

dedicated to carbon oxides) to give a good insight of the different reactive paths, as summarized in Figs. 8 and 9.

The "zip" mechanism proposed by Delprat [2] allows explanation of the high amounts of acetone rather than further reactions undergone by methyl ketones. However, according to Bernstein et al. [8], the radical attack in $\gamma$ position of a methyl ketone would explain the generation of 2,4 pentanedione. Formaldehyde generation is reported according to the mechanism of Hoff and Jacobsson, which consists of the oxidation of primary alkyl radicals [11,12].

Concerning methyl acrolein, although a mechanism has already been proposed [8], its low probability led us to consider an alternative reaction generating a chain scission

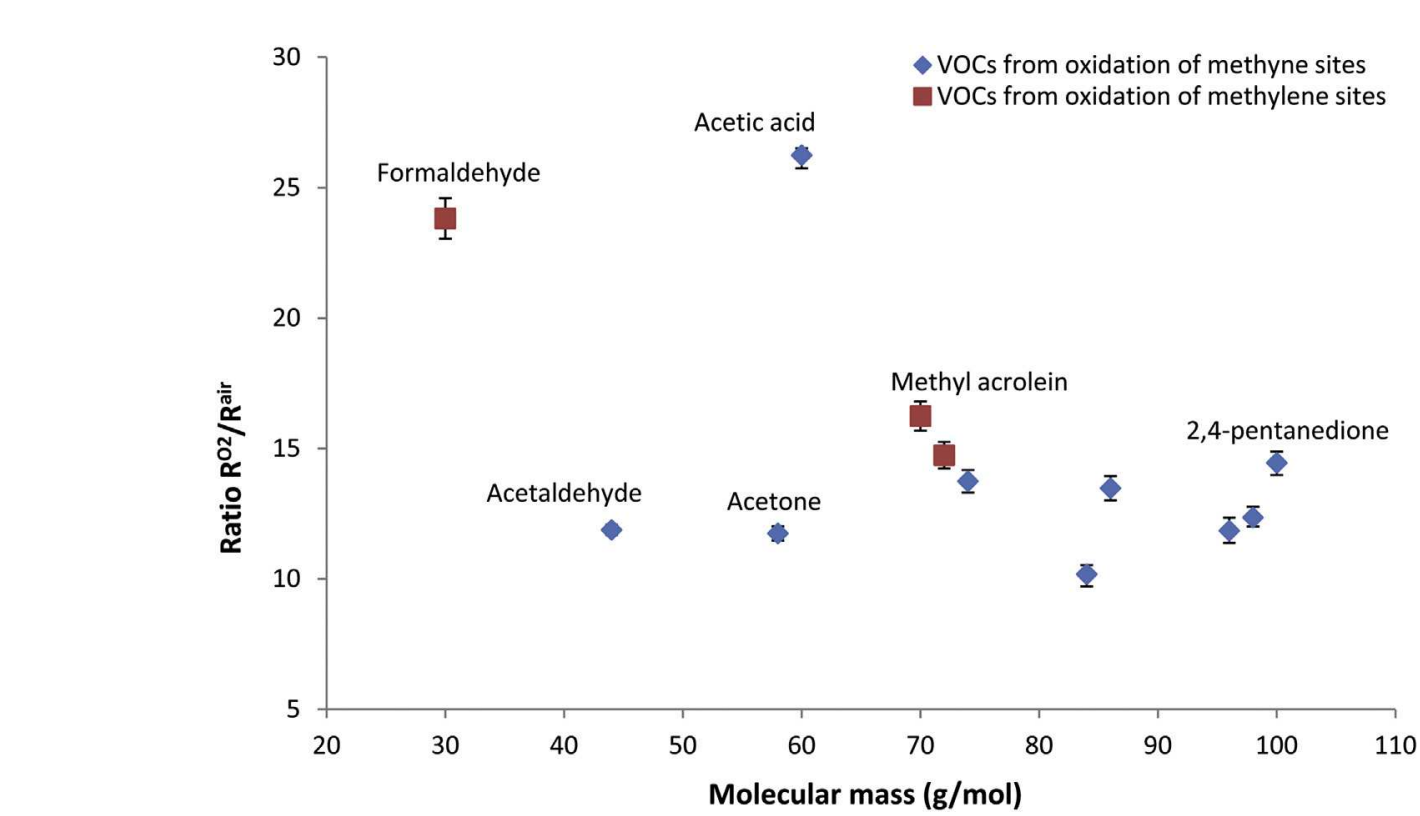

directly from alkyl radicals. The resulting allylic methylenes are highly reactive. Their rapid oxidation would explain the amounts of methyl acrolein detected by PTR-FTICR. Finally, secondary alkyl radicals, generated in the same reactions as methyl acrolein and formaldehyde, would lead to the formation of secondary hydroperoxides, whose $\beta$-scission would result to acetaldehyde according to Hoff and Jacobsson [11,12]. As a competitive route, these secondary alkyl radicals would also lead to macro-aldehydes, whose oxidation followed by a radical attack in $\gamma$ position is preferred to explain the formation of acetic acid, rather than the complex recombination of methyl ketone with an hydroxyl radical $\mathrm{HO}^{\circ}$ proposed by Geuskens [31,32].

Fig. 7. Ratio between the formation rates of VOCs in pure oxygen and air versus their molecular mass. Values are determined for maximal VOCs emission rates. 


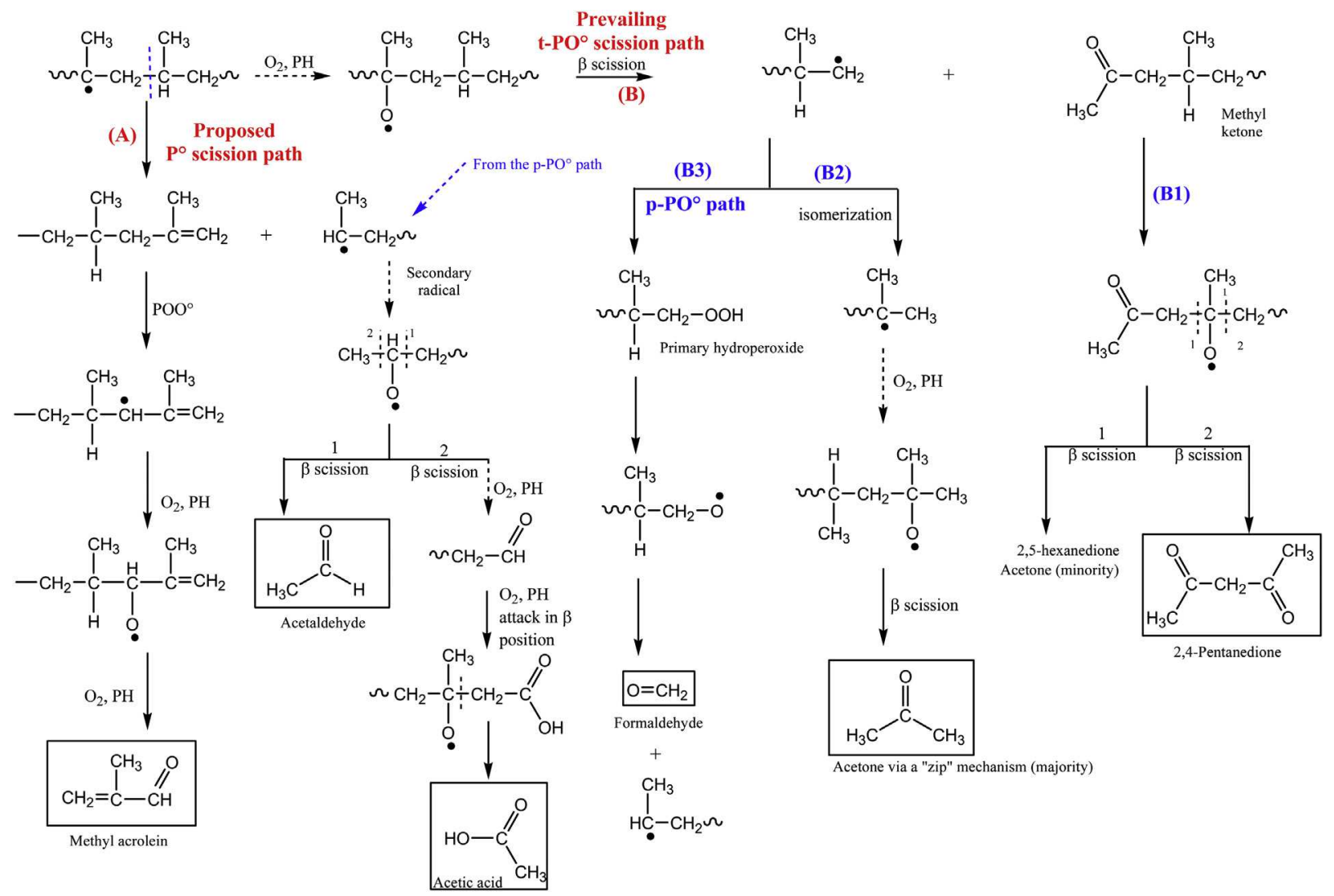

Fig. 8. Mechanistic scheme of formation for the six main VOCs.

Concerning the formation of carbon monoxide and dioxide, the present work does not enable identification of the reactive sites (methyne or methylene units) responsible for this generation, so it is relevant to comprehend it on the basis of the very valuable work of Thornberg et al. [33]. By NMR on $\mathrm{C}^{13}$ isotope labeled PP aged at $140{ }^{\circ} \mathrm{C}$ at air, they showed that methylene units generate about $66 \mathrm{~mol} \%$ of $\mathrm{CO}_{2}$ and more than $80 \mathrm{~mol} \%$ of $\mathrm{CO}$, whereas methyne units generate only $33 \mathrm{~mol} \%$ of $\mathrm{CO}_{2}$ and $5-15 \mathrm{~mol} \%$ of $\mathrm{CO}$. Thus, carbon oxides come mainly from oxidation of methylene units but the part coming from oxidation of methyne units cannot be neglected. The high amounts of carbon oxides resulting from the oxidation of methylene units evidence the prevalence of their formation path involving primary hydroperoxides. This is consistent with the generation of high concentrations of peroxy-acids reported in polypropylene oxidation [34,35]. However, in the case of methyne oxidized unit, the proposed mechanism seems unlikely as written, even if the isotope labeling is unarguable. Consistent with the latter published isotope labeling results, we propose a route for the formation of these later compounds from secondary alkyl radical, as proposed above in the cases of acetaldehyde and acetic acid.

Finally, all these chemical mechanisms can be organized into two competitive pathways:

(i) The "t-Po scission path", noted (A): the decomposition of tertiary alkyl radicals results in relatively unstable allylic methylenes and leads to methyl acrolein. This mechanism enables explanation of additional chain scission and generating carbon dioxide and monoxide from methyne units (Fig. 9). Anyway, these mechanisms would account for a low extent of PP thermal degradation, and require a radical initiation.

(ii) The "t-PO ${ }^{\circ}$ scission path", noted (B): the decomposition of tertiary alkoxy radicals generates methyl ketones and primary alkyl radical. The former species can undergo further vicinal oxidation to give 2,4pentanedione (B1). The latter species can isomerize in tertiary alkyl radicals to lead to acetone (B2), or undergo directly an oxidation to generate formaldehyde, denoted as $\mathrm{p}-\mathrm{PO}^{\circ}$ sub-path (B3).

Along these reactions, acetaldehyde can be produced by cleavage of secondary hydroperoxides according to the paths (A) and (B3).

The general mechanistic scheme of Fig. 5 allows explanations of the amounts of the six main VOCs, in particular the high amounts of acetone, acetic acid, formaldehyde and, in a minor extent, of acetaldehyde can be correlated to the high amounts of radicals formed in the various reaction paths. In both air and pure oxygen, the amount of methyl acrolein remains rather low compared to other VOCs, thus indicating that the " $t-\mathrm{P}^{\circ}$ path" is secondary compared to the "t- $\mathrm{PO}^{\circ}$ path".

When considering the previous mechanisms organized in main paths, it is now possible to comment on the 


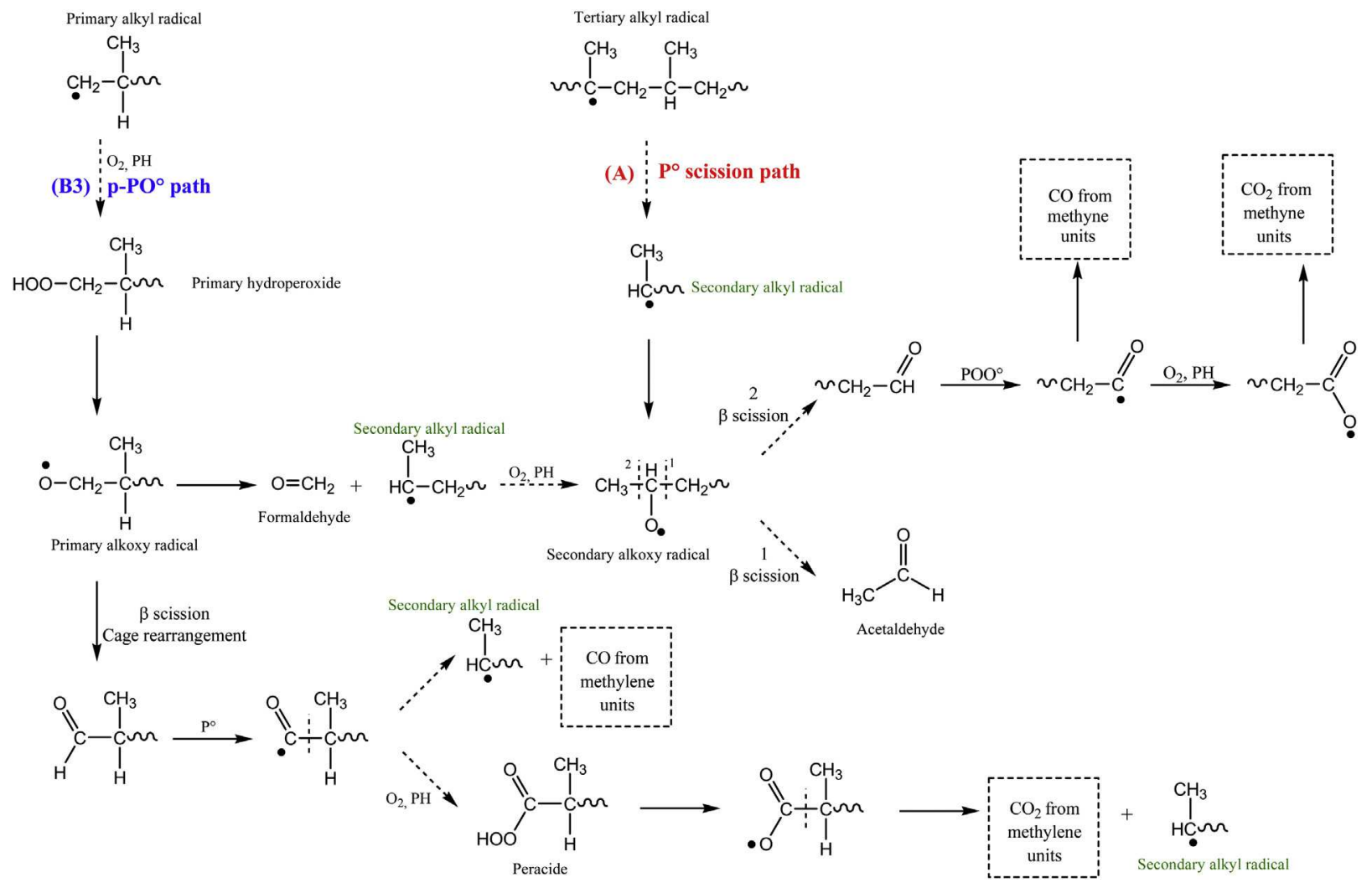

Fig. 9. Mechanisms of carbon oxides formation.

changes of VOCs distribution depending on the oxygen pressure. Ranking VOCs by their relative proportions gives an idea of the prevailing mechanisms in both air and pure oxygen. Surprisingly, the predominance of the "t-PO ${ }^{\circ}$ scission path" over the " $\mathrm{t}-\mathrm{P}^{\circ}$ " one is not dramatically enhanced when increasing the oxygen partial pressure. This would result from the fact that the pressure increase is very low in comparison to the high increase required to reach the critical oxygen partial pressure. On the contrary, such an increase seems to favor "p-PO ${ }^{\circ}$ path" over "t-PO". Indeed, oxygen addition to primary alkyl radicals seems to be dramatically enhanced when increasing the oxygen partial pressure. At this stage of investigation, it is important to underline that nowhere in the previous proposal of mechanistic scheme (Fig. 5) do methylene units undergo a radical attack. The radical attack only occurs on methyne units, leading to the formation of $\mathrm{t}-\mathrm{PO}^{\circ}$ radicals of which the $\beta$ scission generates primary alkyl radicals. Thus, the depletion of methylene units would be an indirect consequence of the PP thermal oxidation.

Previous results obtained in the molten state [24] can also be analyzed on the basis of the proposed global scheme. Indeed, amounts of acetone, acetaldehyde, formaldehyde and, to a lower extent, of methyl acrolein are considerably enhanced above the melting point at $256^{\circ} \mathrm{C}$ in the molten state, whereas acetic acid and 2,4-pentanedione are really minority products. The higher proportion of methyl acrolein indicates that the $t-\mathrm{P}^{\circ}$ path $(\mathrm{A})$ becomes more important with temperature, which is consistent with a thermolysis reaction. Simultaneously, the formation of acetone through the "zip" mechanism (B2) and formation of primary hydroperoxides (B3) are enhanced at the expense of the further reactions undergone by methyl ketones (B1). Similarly, the secondary radicals produced by decomposition of primary hydroperoxides mostly convert into acetaldehyde and carbon oxides rather than acetic acid.

\section{Conclusions}

PTR-FTICR was successfully used to detect, identify and quantify a large number of VOCs generated during PP thermal oxidation. Six main VOCs were clearly evidenced at $140{ }^{\circ} \mathrm{C}$ under both air and pure oxygen, consistent with previous literature. In air, they were, from the major to the minor, acetone, acetic acid, 2,4-pentanedione, acetaldehyde, formaldehyde and methyl acrolein. Real time monitoring of VOCs allowed us to describe a general thermal oxidation scenario, which remains in perfect agreement with thermogravimetric and FTIR analyses. The high amounts of VOCs including small volatile molecules would lead to underestimate the overall oxidation rate determined by a factor from 2 up to 5 , as determined by these two latter complementary techniques.

In terms of mechanisms, it was shown that only methyne units undergo radical attacks, through a majority $\mathrm{t}-\mathrm{PO}^{\circ}$ path and a minority $\mathrm{t}-\mathrm{P}^{\circ}$ path. Oxidation of methylene units only results from subsequent reactions of the 
former path. The influence of oxygen pressure on the relative proportions of VOCs does not express itself into the competition between the $\mathrm{t}-\mathrm{PO}^{\circ}$ and $\mathrm{t}-\mathrm{P}^{\circ}$ scission paths, but rather from the its competition with the $\mathrm{PO}^{\circ}$ path. In particular, oxygen addition to primary alkyl radicals leading to primary hydroperoxides seems to be highly impacted by a small increase in oxygen partial pressure far below the critical oxygen pressure. This would lead us to fear considerable changes on the equivalence and/or validity of the oxidation monitoring criteria depending on oxygen pressure.

Regarding these conclusions, several outlooks can be outlined in terms of kinetic modeling. It seems relevant to consider methyne units as the unique driving oxidation sites, thus strengthening the relevancy of the "closed loop" mechanistic scheme while demarcating its limits to tackle modeling of advanced state of degradation. Indeed, there are few incentives to model such complex imbrications of reactions with their own oxygen pressure dependence. Instead, it is possible from the present results to suitably estimate apparent parameters for common oxidation monitoring indicators, such as the yield in carbonyl products or the equivalent molecular mass of volatiles respectively for carbonyl index and mass loss.

\section{References}

[1] S. Commereuc, D. Vaillant, J.L. Philippart, J. Lacoste, J. Lemaire, D.J. Carlsson, Photo and thermal decomposition of iPP hydroperoxides, Polymer Degradation and Stability 57 (1997) 175-182.

[2] P. Delprat, X. Duteurtre, J.-L. Gardette, Photooxidation of unstabilized and HALS-stabilized polyphasic ethylene-propylene polymers, Polymer Degradation and Stability 50 (1995) 1-12.

[3] J.-L. Philippart, F. Posada, J.-L. Gardette, Mass spectroscopy analysis of volatile photoproducts in photooxidation of polypropylene, Polymer Degradation and Stability 49 (1995) 285-290.

[4] Robert Bernstein, M. Steven Thornberg, N. Adriane Irwin, M. James Hochrein, K. Dora Derzon, B. Sara Klamo, L. Roger Dough, Radiation-oxidation mechanisms: volatile organic degradation products from polypropylene having selective $\mathrm{C}-13$ labeling studied by GC/MS, Polymer Degradation and Stability 93 (2008) 854-870.

[5] R. Bernstein, S.M. Thornberg, R.A. Assink, D.M. Mowery, M. Kathleen Alam, A.N. Irwin, J.M. Hochrein, D.K. Derzon, S.B. Klamo, R.L. Clough, Insights into oxidation mechanisms in gamma-irradiated polypropylene, utilizing selective isotopic labeling with analysis by GC/ MS, NMR and FTIR, Nuclear Instruments and Methods in Physics Research Section B: Beam Interactions with Materials and Atoms 265 (2007) 8-17.

[6] R. Buchalla, C. Boess, K.W. Bögl, Analysis of volatile radiolysis products in gamma-irradiated LDPE and polypropylene films by thermal desorption-gas chromatography-mass spectrometry, Applied Radiation and Isotopes 52 (2000) 251-269.

[7] K. Barabás, M. Iring, S. László-Hedvig, T. Kelen, F. Tüdos, Study of the thermal oxidation of polyolefins-VIII: Volatile products of polypropylene thermal oxidation, European Polymer Journal 14 (1978) 405-407.

[8] R. Bernstein, S.M. Thornberg, R.A. Assink, A.N. Irwin, J.M. Hochrein, J.R. Brown, D.K. Derzon, S.B. Klamo, R.L. Clough, The origins of volatile oxidation products in the thermal degradation of polypropylene, identified by selective isotopic labeling, Polymer Degradation and Stability 92 (2007) 2076-2094.

[9] Z. Czégény, E. Jakab, A. Víg, B. Zelei, M. Blazsó, Thermal decomposition of photooxidized isotactic polypropylene, Journal of Analytical and Applied Pyrolysis 56 (2000) 229-242.

[10] J.-i. Hayashi, T. Nakahara, K. Kusakabe, S. Morooka, Pyrolysis of polypropylene in the presence of oxygen, Fuel Processing Technology 55 (1998) 265-275.

[11] A. Hoff, S. Jacobsson, Thermal oxidation of polypropylene close to industrial processing conditions, Journal of Applied Polymer Science 27 (1982) 2539-2551.
[12] A. Hoff, S. Jacobsson, Thermal oxidation of polypropylene in the temperature range of $120-280^{\circ} \mathrm{C}$, Journal of Applied Polymer Science 29 (1984) 465-480.

[13] S.G. Kiryushkin, A.P. Mar'in, Y.A. Shlyapnikov, Annular reactor for chromatographic analysis of gases formed by thermal breakdown of polymers, Polymer Science U.S.S.R 22 (1980) 1570-1574.

[14] G.B. Willoughby, A. Golby, J. Davies, R. Cain, Volatile component analysis as a routine characterisation tool: an approach to fingerprinting polyolefin type and process history using ATD-GC/MS, Anglais 22 (2003) 553-570.

[15] H.A. Frostling, S. Jacobsson, P. Pfäffli, S. Vainiotalo, A. Zitting, Analytical, occupational and toxicologic aspects of the degradation products of polypropylene plastics, Scand J Work Environ Health 10 (1984) 163-169.

[16] D.J. Carlsson, D.M. Wiles, The photooxidative degradation of polypropylene. Part I, Photooxidation and Photoinitiation Processes 14 (1976) 65-106.

[17] D.M. Mowery, R.A. Assink, D.K. Derzon, S.B. Klamo, R.L. Clough, R. Bernstein, Solid-state 13C NMR investigation of the oxidative degradation of selectively labeled polypropylene by thermal aging and $\hat{\mathrm{I}}^{3}$-irradiation, Macromolecules 38 (2005) 5035-5046.

[18] J. Lacoste, D. Vaillant, D.J. Carlsson, Gamma-, photo-, and thermallyinitiated oxidation of isotactic polypropylene, Journal of Polymer Science Part A: Polymer Chemistry 31 (1993) 715-722.

[19] L. Audouin, V. Gueguen, A. Tcharkhtchi, J. Verdu, Close loop mechanistic schemes for hydrocarbon polymer oxidation, Journal of Polymer Science Part A: Polymer Chemistry 33 (1995) 921-927.

[20] B. Fayolle, L. Audouin, J. Verdu, A critical molar mass separating the ductile and brittle regimes as revealed by thermal oxidation in polypropylene, Polymer 45 (2004) 4323-4330.

[21] J. Rychly, L. Matisova-Rychla, K. Csmorova, L. Achimsky, L. Audouin, A. Tcharkhtchi, J. Verdu, Kinetics of mass changes in oxidation of polypropylene, Polymer Degradation and Stability 58 (1997) 269-274.

[22] Xavier Colin, Emmanuel Richaud, Jacques Verdu, Carole L. Monchy, Kinetic modelling of radiochemical ageing of ethylene-propylene copolymers, Radiation Physics and Chemistry 79 (2010) 365-370.

[23] J.C.W. Chien, H. Jabloner, Polymer reactions. IV. Thermal decomposition of polypropylene hydroperoxides, Journal of Polymer Science Part A-1: Polymer Chemistry 6 (1968) 393-402.

[24] S. Sarrabi, X. Colin, A. Tcharkhtchi, M. Heninger, J. Leprovost, H.l.n. Mestdagh, Real time analysis of volatile organic compounds from polypropylene thermal oxidation using chemical ionization Fourier transform ion cyclotron resonance mass spectrometry, Analytical Chemistry 81 (2009) 6013-6020.

[25] E. Richaud, F. Farcas, P. Bartoloméo, B. Fayolle, L. Audouin, J. Verdu, Effect of oxygen pressure on the oxidation kinetics of unstabilised polypropylene, Polymer Degradation and Stability 91 (2006)398-405.

[26] X. Colin, L. Audouin, J. Verdu, Determination of thermal oxidation rate constants by an inverse method. Application to polyethylene, Polymer Degradation and Stability 86 (2004) 309-321.

[27] G. Mauclaire, J. Lemaire, P. Boissel, G. Bellec, M. Heninger, MICRA: a compact permanent magnet Fourier transform ion cyclotron resonance mass spectrometer, European Journal of Mass Spectrometry 10 (2004) 155-162.

[28] L. Matisova-Rychla, J. Rychly, J. Verdu, L. Audouin, K. Csomorova, Chemiluminescence and thermogravimetric study of thermal oxidation of polypropylene, Polymer Degradation and Stability 49 (1995) 51-55.

[29] P. Eriksson, T. Reitberger, B. Stenberg, Gas-phase contribution to the spreading of oxidation in polypropylene as studied by imaging chemiluminescence, Polymer Degradation and Stability 78 (2002) 183-189.

[30] D. Vaillant, J. Lacoste, G. Dauphin, The oxidation mechanism of polypropylene: contribution of 13C-NMR spectroscopy, Polymer Degradation and Stability 45 (1994) 355-360.

[31] G. Geuskens, M.S. Kabamba, Photo-oxidation of polymers - part V: a new chain scission mechanism in polyolefins, Polymer Degradation and Stability 4 (1982) 69-76.

[32] G. Geuskens, M.S. Kabamba, Photo-oxidation of polymers: part IX additional comments about a new chain scission mechanism in polyolefins, Polymer Degradation and Stability 5 (1983) 399-401.

[33] S.M. Thornberg, R. Bernstein, A.N. Irwin, D.K. Derzon, S.B. Klamo, R.L. Clough, The genesis of $\mathrm{CO}_{2}$ and $\mathrm{CO}$ in the thermooxidative degradation of polypropylene, Polymer Degradation and Stability 92 (2007) 94-102

[34] P. Gijsman, J. Hennekens, J. Vincent, The mechanism of the lowtemperature oxidation of polypropylene, Polymer Degradation and Stability 42 (1993) 95-105.

[35] P. Gijsman, M. Kroon, M. van Oorschot, The role of peroxides in the thermooxidative degradation of polypropylene, Polymer Degradation and Stability 51 (1996) 3-13. 